\title{
Polyacetylene Compound from Cirsium japonicum var. ussuriense Inhibits the LPS-Induced Inflammatory Reaction via Suppression of NF-kB Activity in RAW 264.7 Cells
}

\author{
Tae Jin Kang ${ }^{1,3}$, Jung Sun Moon ${ }^{2,3}$, Sookyeon Lee ${ }^{2,3}$ and Dongsool Yim ${ }^{2,3, *}$ \\ ${ }^{1}$ Institute of Chronic Disease, ${ }^{2}$ Traditional Medicines Research Institute, ${ }^{3}$ College of Pharmacy, Sahmyook University, \\ Seoul 139-742, Republic of Korea
}

\begin{abstract}
Cirsium japonicum var. ussuriense is known to have a variety of biological activities, including anti-inflammatory, analgesic activity and antipyretic activity. In this study we investigated the role of polyacetylene compound, 1-Heptadecene-11, 13-diyne-8, 9, 10-triol (PA) from the root of Cirsium japonicum var. ussuriense as an immune-modulator. PA was evaluated as inhibitors of some macrophage functions involved in the inflammatory process. We tested the effect of PA on the production of pro-inflammatory cytokines, interleukin-1beta (IL-1 $\beta$ ) and tumor necrosis factor-alpha (TNF- $\alpha$ ), and nitric oxide (NO) in murine macrophage cell line, RAW264.7. There was no effect on cytokine production of macrophages by PA itself. However, PA inhibited lipopolysaccharide (LPS)-induced IL-1 $\beta$ and TNF- $\alpha$ production by macrophages at a dose dependent manner. PA also suppressed the NO production of macrophages by LPS. LPS-induced NF- $\mathrm{B}$ activity was decreased by treatment of PA. Therefore, these results suggest that PA has anti-inflammatory effect by inhibiting the NF-kB activation.
\end{abstract}

Key Words: Polyacetylene compound, Cirsium japonicum var. ussuriense, Anti-inflammatory activity, RAW264.7 cell

\section{INTRODUCTION}

Inflammation is a complex and an essential protective response by the host immune system against physical, chemical and infective agents. However, it is frequent that inflammatory response to several stimuli leads to the damaging of normal tissues (Nathan, 2002; Rankin, 2004; Cho et al., 2008).

Macrophages are innate immune cells and activation of macrophages plays an important role in the processes of several inflammatory diseases. Activated macrophages can produce various pro-inflammatory cytokines which may exert inflammatory effects. Inhibition of macrophages activation may alleviate inflammation under these conditions. The major cytokines that mediate inflammation are IL-1 $\beta$ and TNF- $\alpha$. IL-1 $\beta$ and TNF- $\alpha$ share many biologic properties. Nitric oxide (NO) also plays an important role in vascular function during inflammatory responses. Their secretion can be stimulated by lipopolysaccharide (LPS), immune complexes, toxins, physical injury, and a variety of inflammatory processes. Nuclear factor-kappa $\mathrm{B}(\mathrm{NF}-\mathrm{\kappa} \mathrm{B})$ is an important transcription factor and regulates various cellular genes and protein involved in immune and inflammatory responses, such as iNOS, tumor necrosis factor (TNF)- $\alpha$ and interleukin (IL)-6.
Cirsium japonicum var. ussuriense belongs to the compositae family and is perennial plant, $0.5-2.0 \mathrm{~m}$ in height, possessing lance-shaped, spiny-toothed leaves, and white to purple flowers. Most plants of the Compositae family have been traditionally used in oriental medicine as an analgesic, diuretic, anti phlogistics, hemostatic, and detoxifying agents (Ganzera et al., 2005). Linarin, luteolin, acacetin etc. from the Compositae family has been reported to have various biological activities including anti-oxidant activity (Park et al., 2004; Jeong et al., 2008). However, no report has been issued on anti-inflammatory activity or mode of action by 1-Heptadecene-11, 13-diyne-8, 9, 10-triol (PA) from the root of Cirsium japonicum var. ussuriense.

To search for the novel therapeutic agents against inflammatory diseases, therefore, the present study was designed to explore the potential anti-inflammatory effects of PA from the root of Cirsium japonicum var. ussuriense. We tested the effect of PA on the production of pro-inflammatory cytokines, IL-1 $\beta$ and TNF- $\alpha$, and NO in mouse macrophage cell line, RAW264.7. www.biomolther.org

Open Access DOI: 10.4062/biomolther.2011.19.1.097

pISSN: 1976-9148 elSSN: 2005-4483

Copyright $\odot 2011$ The Korean Society of Applied Pharmacology
Received Aug 16, 2010 Revised Oct 16, 2010 Accepted Oct 18, 2010

*Corresponding Author
E-mail: yimds@syu.ac.kr
Tel: +82-2-3399-1604, Fax: +82-2-3399-1617 


\section{MATERIALS AND METHODS}

\section{Plant material, isolation and characterization of poly- acetylene compound}

The root of Cirsium japonicum var. ussuriense (Compositae), which was collected in Kyunggi Province Korea May, 2007 and identified by Prof. Sookyeon Lee, of Sahmyook University. The voucher specimen (SYU-2007-01) was deposited at the Herbarium of the Sahmyook University.

\section{Isolation and preparation of polyacetylene compound}

The air-dried plant material (root, $1 \mathrm{~kg}$ ) was sliced and extracted with $70 \%$ hot $\mathrm{MeOH}$ three times for 3 hours each. The extract was filtered, and concentrated in vacuo to get a $\mathrm{MeOH}$ extract. The concentrated extract $(200 \mathrm{~g})$ was suspended in water and then partitioned with $n$-hexane successively by EtOAc and $n$-Butanol to afford three fractions and an aqueous residue. The $\mathrm{BuOH}$ extracts obtained by removal of the solvent. Polyacetylene compound (PA) was isolated from $\mathrm{BuOH}$ fraction by silica gel column chromatography with gradient elution with $\mathrm{MeOH}$ and $\mathrm{CHCl}_{3}$. This compound was characterized by NMR (Bruker AVANCE 400 NMR spectrometer). The purified PA, 1-Heptadecene-11, 13-diyne-8, 9, 10-triol with a molecular weight of 278 (Fig. 1), was dissolved in dimethylsulfoxide (DMSO) (Sigma-Aldrich Korea, Yongin-city, Kyunggi-do, Korea) as stock solution, used directly for cell culture treatment. The final concentration of DMSO in the culture media was $1.0 \%$, which did not show any effect in the assay system.

\section{Cell culture and treatments}

Murine macrophage cell line, RAW 264.7 cells were cultured in Dulbecco's Modified Eagle's Medium supplemented with $20 \mathrm{mM}$ HEPES, $10 \%$ FBS, $100 \mathrm{U} / \mathrm{ml}$ of penicillin, and $100 \mu \mathrm{g} / \mathrm{ml}$ of streptomycin (Sigma-Aldrich Korea). The RAW cells were plated onto 6 -well plate at $2 \times 10^{6}$ cells per well and incubated overnight. The cells were pretreated with various concentration of PA for $1 \mathrm{~h}$ and then treated with LPS (100 ng/ $\mathrm{ml}$, Sigma-Aldrich Korea) from E. coli O111:B4 for $24 \mathrm{~h}$.

\section{Measurement of cell viability}

Trypan blue (Sigma-Aldrich Korea) exclusion was used to

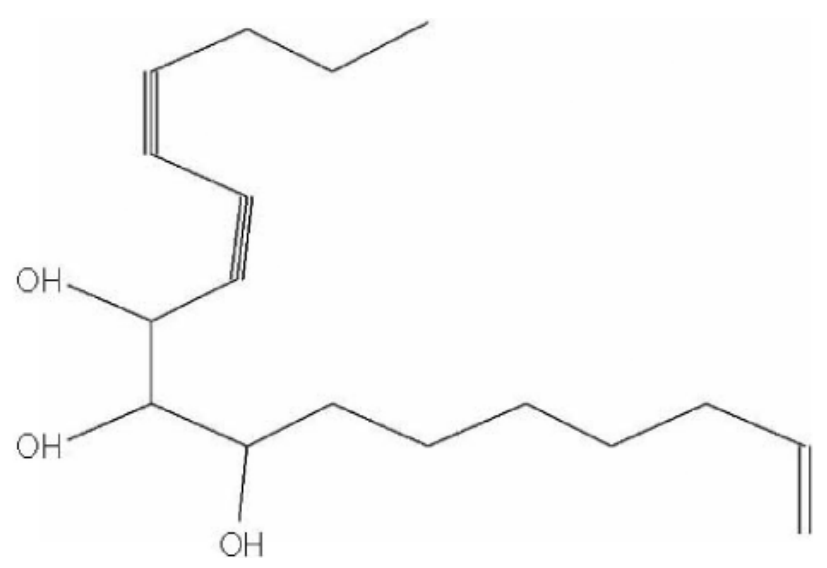

Fig. 1. The structure of polyacetylene compound (PA), 1-Heptadecene-11, 13-diyne-8, 9, 10-triol from the root of Cirsium japonicum var. ussuriense. determine viable and dead cells to test cytotoxicity of PA. MTT (Methylthiazolyldiphenyl-tetrazolium bromide, Sigma-Aldrich Korea) assay was also used to measure the cytotoxicity on the cells with PA.

\section{Cytokine assay}

Cell culture supernatants were assayed for mouse IL-1 $\beta$ (eBioscience, San Diego, CA, USA) and TNF- $\alpha$ (Pharmingen, BD Biosciences, San Diego, CA, USA) by ELISA.

\section{Nitric oxide determination}

NO levels were measured with cell culture supernatants by Griess reaction. Briefly, $50 \mu \mathrm{l}$ samples were incubated with 50 $\mu \mathrm{l}$ of $1 \%$ sulfanilamide (Sigma-Aldrich Korea) solution and 50 $\mu \mathrm{l}$ of $0.1 \% \mathrm{~N}$-1-naphtylethylenediamine dihydrochloride (Sigma-Aldrich Korea) solution at room temperature for $10 \mathrm{~min}$. The data was recorded and analyzed using SOFTmax version 4.6 software (Molecular Devices, Menlo Park, CA).

\section{NF- $\kappa B$ activity}

Cytosolic and nuclear extracts were isolated and assayed

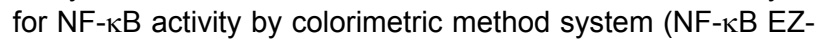
TFA Transcription Factor Assay, Upstate \& Millipore, Billerica, MA, USA) according to the manufacturer's instruction.

\section{Statistical analysis}

All data and statistical analyses were carried out using SigmaStat, version 3.1 , by one-way analysis of variance (ANO$\mathrm{VA}$ ), and significance was accepted at $p<0.05$.

\section{RESULTS}

NMR characterization of polyacetylene compound (PA)

${ }^{1} \mathrm{H}-\mathrm{NMR}\left(400 \mathrm{MHz}, \mathrm{CDCl}_{3}\right) \delta: 0.98,(t, \mathrm{H}-17), 1.2-1.6(\mathrm{H}-4-$ 7), $2.09(m, \mathrm{H}-3), 2.27(t, J=7.1 \mathrm{~Hz}, \mathrm{H}-15), 3.53(d d, J=4.2 \mathrm{~Hz}$, $\mathrm{H}-9), 4.04$ (td, H-8), 4.58 (d, H-10), 5.01 (d, H-1), 5.26 (dd, $\mathrm{H}-9), 5.54(d, \mathrm{H}-10), 5.81(d t, \mathrm{H}-2)$, FABMS m/z: 301[M+Na+], $279\left[\mathrm{M}+\mathrm{H}^{+}\right], 261,243$.

\section{Cytotoxicity of PA to RAW $\mathbf{2 6 4 . 7}$ cells}

The cytotoxic effect of PA was evaluated in RAW 264.7 cells using MTT assay and trypanblue exclusion method, but no effect on cell viability was observed at the concentrations used and at even higher dose, $400 \mu \mathrm{M}$, which showed the inhibitory effect on pro-inflammatory cytokines production (data not shown).

\section{Inhibitory effect of PA on pro-inflammatory cytokines production}

As a part of our screening study to evaluate the anti-inflammatory potentials of natural compounds for the development of new anti-inflammatory drug, we investigated the in vitro anti-inflammatory activity of the PA from the root of Cirsium japonicum var. ussuriense. It has been reported that cytokines, such as TNF- $\alpha$ and IL-1 $\beta$, are pro-inflammatory mediators in vitro and in vivo (Feldmann et al., 1991). To assess whether PA inhibits the pro-inflammatory mediators, we first investigated the effect of PA $(50,100,200$, and $400 \mu \mathrm{M})$ on LPS-induced TNF- $\alpha$ and IL- $1 \beta$ release in RAW 264.7 cells by ELISA. Our data showed that PA markedly suppressed LPS-induced IL-1 $\beta$ 
and TNF- $\alpha$ production by macrophages at a dose dependent manner (Fig. 2).

\section{Effect of PA inhibited nitric oxide (NO) production by LPS in RAW 264. 7 cells}

It is marked by the accumulation of variety of inflammatory cells and release of several soluble mediators of inflammation such as reactive oxygen species (ROS), lipid mediators, proteases and cytokines (Huerre and Gounon, 1996; Rankin, 2004). Nitric oxides (NOs) are well known pro-inflammatory mediators (Vane et al., 1994). Therefore, we next study the effect of PA on LPS-induced NO production in macrophages. To assess the effect of PA on LPS-induced NO production in RAW 264.7 macrophage cells, cells were treated with or without PA for $1 \mathrm{hr}$, and then with LPS for $24 \mathrm{hrs}$. Cell culture supernatants were collected and NO levels were determined using the Griess reaction (Fig. 3). LPS induced NO production 9-fold more than the control group, and PA inhibited this NO production in a dose-dependent manner in the range of 100$400 \mu \mathrm{M}$ (Fig. 3).

\section{The inhibitory effect of PA on LPS-induced NF- $\kappa B$ activa- tion in macrophages}

$\mathrm{NF}-\kappa \mathrm{B}$ is known to play a critical role in the regulation of genes and proteins involved in cell survival and inflammation. To explore the mechanism of the effects of PA on LPS-induced inflammation in RAW 264.7 macrophage cells, the protein levels of NO, TNF- $\alpha$, and IL- $1 \beta$ were examined. PA suppressed the release of $\mathrm{NO}$ (Fig. 3) and proinflammatory cytokines, TNF- $\alpha$ and IL-1 $\beta$ proteins, in a dose-dependent manner (Fig. 2). Thus, we postulated that the inhibitory effect of PA on proinflammatory cytokines release may be associated with the
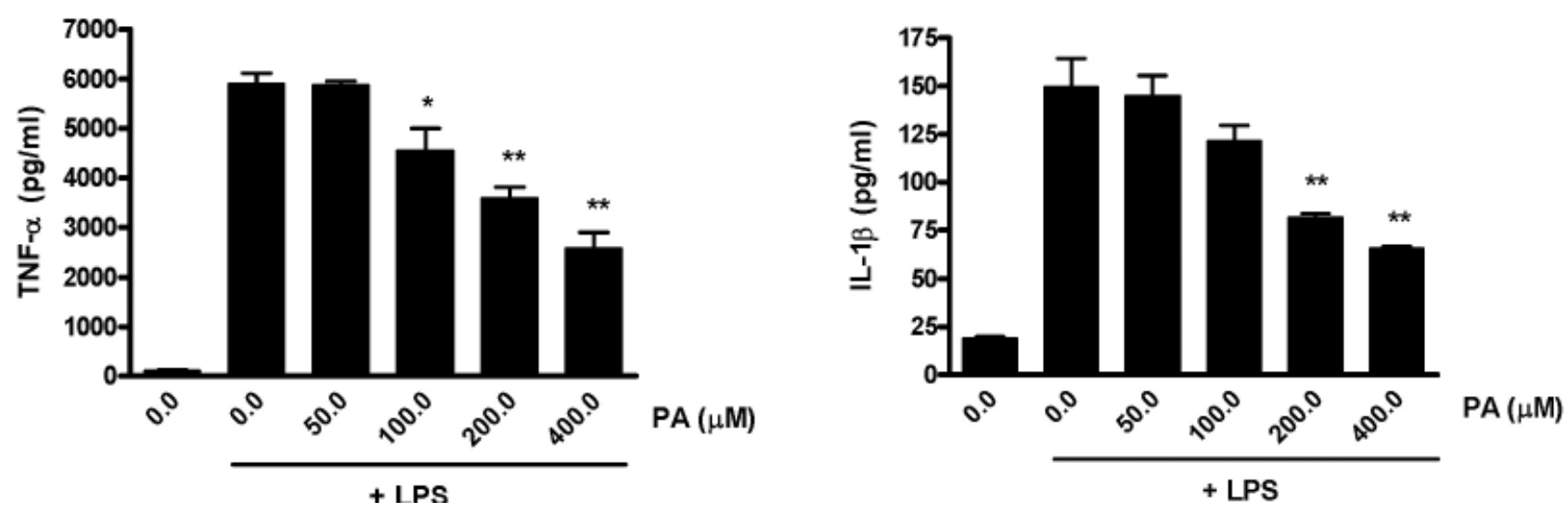

Fig. 2. The induction of IL-1 $\beta$ and TNF- $\alpha$ secretions by LPS were inhibited with treatment of PA at a dose dependent manner in RAW 264.7 cells. RAW264.7 cells were plated on 12 well cell culture plate, treated with or without PA at a dose dependent manner (50-400 $\mu \mathrm{M})$ for 1 $\mathrm{hr}$, and then with LPS $(100 \mathrm{ng} / \mathrm{ml})$. After $24 \mathrm{~h}$ of these treatments, cell culture supernatants were collected for cytokine (IL-1 $\beta$ and TNF- $\alpha$ ) assay. Data are representative of at least three independent experiments, each done in triplicate; ${ }^{*} p<0.05,{ }^{* *} p<0.01$ compared to control groups treated with LPS alone.

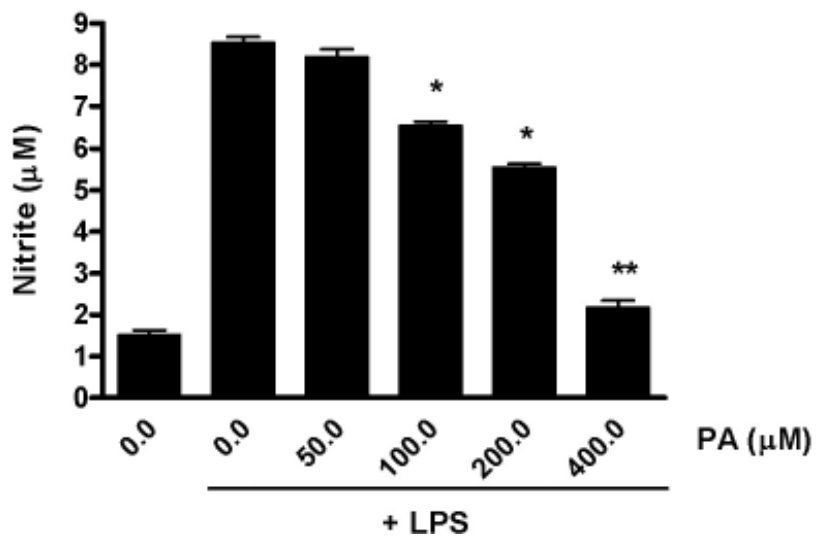

Fig. 3. The induction of nitric oxide by LPS was also inhibited with treatment of PA at a dose dependent manner in RAW 264.7 cells. RAW264.7 cells were treated with or without PA at a dose dependent manner for $1 \mathrm{hr}$, and then with LPS. After $24 \mathrm{~h}$ of these treatments, cell culture supernatants were collected for nitric oxide measurement. Data are representative of at least three independent experiments, each done in triplicate; ${ }^{*} p<0.05$, ${ }^{* *} p<0.01 \mathrm{com}-$ pared to control groups treated with LPS alone.

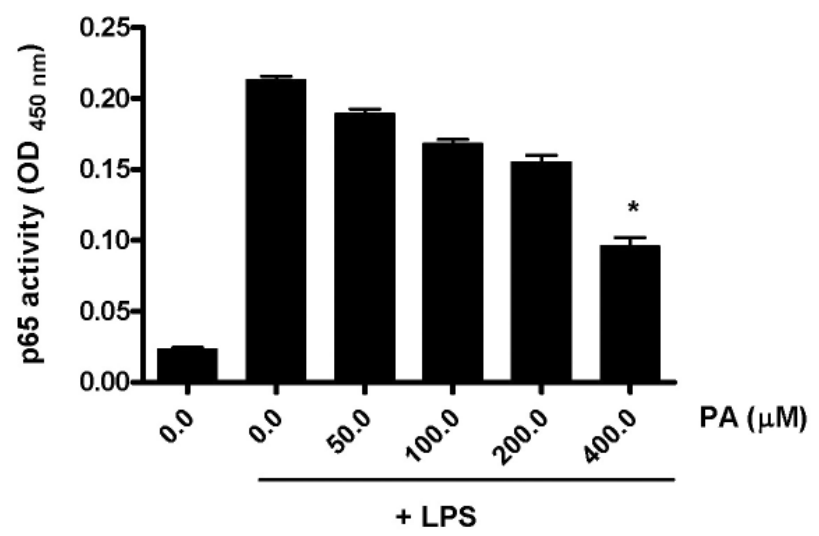

Fig. 4. The treatment of PA also decreased the NF-kB activity induced by LPS at a dose dependent manner. RAW264.7 cells were treated with or without PA at a dose dependent manner for $1 \mathrm{hr}$, and then with LPS. After $24 \mathrm{~h}$ of these treatments, Cytosolic and nuclear extracts were isolated and assayed for NF- $\mathrm{kB}$ activity by the colorimetric method. Data are representative of at least three independent experiments, each done in triplicate; ${ }^{*} p<0.05 \mathrm{com}$ pared to control groups treated with LPS alone. 
transcriptional suppressions of NF- $\kappa \mathrm{B}$.

Since the activation of NF-kB is known to mediate LPSinduced expression of NO and TNF- $\alpha$ (Krasnow et al., 1991; Doyle and O'Neill, 2006), colorimetric assay was performed to determine whether PA suppresses NF- $\kappa B$ activation. The result shows LPS-induced NF- $\mathrm{BB}$ activity was decreased by treatment of PA (Fig. 4).

\section{DISCUSSION}

In the absence of inflammation, wounds and infections would never heal and progressive destruction of the tissue would compromise the survival of the organism. However, chronic inflammation can also lead to some diseases, such as atherosclerosis and rheumatoid arthritis. It is for that reason that inflammation is normally regulated by the body. Despite of many efforts to develop anti-inflammatory agents, there is still a large demand for developing new agents (Cho et al., 2008; Jin et al., 2009). During our research for novel anti-inflammatory agents from natural products, we found that the PA of Cirsium japonicum var. ussuriense inhibits LPS-induced NO and pro-inflammatory cytokines production in a dose-dependent manner.

Macrophages play an important role in the initiation and amplification of a variety of inflammatory disease e.g. septic shock and chronic inflammatory conditions such as asthma, rheumatoid arthritis and Crohn's disease (Gordon, 2007). LPS stimulates toll-like receptor 4 (TLR4) on the surface of macrophages and triggers cytoplasmic adapter proteins, which re-

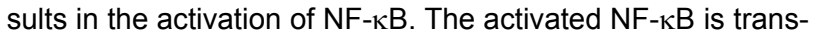
located into the nucleus where it induces the transcription of genes with an NF-KB consensus site in their promoter region, including iNOS and pro-inflammatory cytokines such as TNF$\alpha$, IL- $1 \beta$. TNF- $\alpha$ elicits a number of physiological effects such as septic shock, inflammation, and cachexia (Aggarwal and Natarajan, 1996). IL-1 $\beta$ is a multifunctional cytokine that is responsible for mediating a variety of processes in the host defense response, inflammation, and the response to injury. Macrophages and many other cell types produce IL-1 $\beta$ by the actions of various stimuli such as viruses and LPS, the cell wall component from gram negative bacteria. Since IL-1 $\beta$ is a highly pro-inflammatory cytokines, agents that reduce its production and/or activity might be of a particular pharmacological and clinical interest.

As cytokines are critical to the pathogenesis of inflammatory disorders, inhibition of their production provides therapeutic targets in various inflammatory diseases. In the present study, we have demonstrated that PA significantly inhibits LPS-induced transcriptional activity of NF- $\kappa \mathrm{B}$, consequently resulting in a decrease in the expression of $\mathrm{NO}$ and pro-inflammatory cytokines, TNF- $\alpha$ and IL-1 $\beta$, in RAW 264.7 cells. Therefore, inhibition of the pro-inflammatory cytokines production (Kim et al., 2007) is believed to be one of the pathways by which PA has its anti-inflammatory activity in this study. ASA (Acetyl salicylic acid) was used as a positive control (data not shown). Whereas ASA has EC 50 at concentration of $4 \mathrm{mM}$, EC50 of $\mathrm{PA}$ is at concentration of above $200 \mu \mathrm{M}$.

Caspase- 1 is a cysteine protease originally cloned as IL$1 \beta$-converting enzyme (Cerretti et al., 1992; Thornberry et al., 1992). It is an essential regulator of inflammatory responses through its capacity to process and activate prolL- $1 \beta$ and
prolL-18 (Ogura et al., 2006). Considering that the release of $\mathrm{IL}-1 \beta$ protein is dependent on the activation of caspase- 1 , further study is necessary to elucidate the exact mechanism of PA actions in terms of caspase-1 activation and its regulation.

In summary, these findings suggest that PA is a potent inhibitor of LPS-induced NO, TNF- $\alpha$, and IL-1 $\beta$ production in RAW 264.7 macrophage cells. Moreover, these inhibitory effects of PA were found to be associated with NF- $\kappa B$ inactivation. Since NF- $\kappa B$ is a transcription factor that regulates the transcriptions of many inflammation-related genes, its inhibition by PA may offer a possible approach to the prevention or treatment of severe inflammatory diseases.

\section{ACKNOWLEDGMENTS}

This work was supported by the Sahmyook University Research Fund in 2008.

\section{REFERENCES}

Aggarwal, B. B. and Natarajan, K. (1996) Tumor necrosis factors: developments during the last decade. Eur. Cytokine. Netw. 7, 93-124.

Cerretti, D. P., Kozlosky, C. J., Mosley, B., Nelson, N., Van Ness, K., Greenstreet, T. A., March, C.J., Kronheim, S. R., Druck, T., Cannizzaro, L. A., Huebner, K. and Black, R. A. (1992) Molecular Cloning of the interleukin-1 beta converting enzyme. Science 256, 97-100.

Cho, W., Park, S. J., Shin, J. S., Noh, Y. S., Cho, E. J., Nam, J. H. and Lee, K. T. (2008) Anti-inflammatory effects of the methanol extract of Polytrichum Commune via NF-kB inactivation in RAW 264.7 macrophage cells. Biomol. \& Ther. 16, 385-393.

Doyle, S. L. and O'Neill, L. A. (2006) Toll-like receptors: from the discovery of NFkappaB to new insights into transcriptional regulations in innate immunity. Biochem. Pharmacol. 72, 1102-1113.

Feldmann, M., Brennan, F. M., Chantry, D., Haworth, C., Turner, M., Katsikis, P., Londei, M., Abney, E., Buchan, G., Barrett, K., Corcoran, A., Kissonerghis, M., Zheng, R., Gruberck-Loebenstein, B., Barkley, D., Chu, C. Q., Field, M. and Maini R. N. (1991) Cytokine assays: role in evaluation of the pathogenesis of autoimmunity. $I \mathrm{~m}$ munol. Rev. 119, 105-123.

Ganzera, M., Pocher, A. and Stuppner, H. (2005) Differentiation of Cirsium japonicum and C. setosum by TLC and HPLC-MS. Phytochem Anal. 16, 205-209.

Gordon, S. (2007) The macrophage: past, present and future. Eur. J. Immunol. 37(Suppl 1), S9-17.

Huerre, M. R. and Gounon, P. (1996) Inflammation: pattern and new concepts. Res. Immunol. 147, 417-434.

Jeong, da M., Jung, H. A. and Choi, J. S. (2008) Comparative antioxidant activity and HPLC profiles of some selected Korean thistles. Arch. Pharm. Res. 31, 28-33.

Jin, M., Bae, J., Chang, H. W. and Son, J. K. (2009) Anti-inflammatory compounds from the leaves of Ailanthus altissima. Biomol. Ther. 17, 86-91.

Kim, J. B., Han, A. R., Park, E. Y., Kim, J. Y., Cho, W., Lee, J.,Seo, E. K. and Lee, K. T. (2007) Inhibition of LPS-induced iNOS, COX-2 and cytokines expression by poncirin through the NF-kappaB inactivation in RAW 264.7 macrophage cells. Biol. Pharm. Bull. 30, 2345-2351.

Krasnow, S. W., Zhang, L. Q., Leung, K. Y., Osborn, L., Kunkel, S. and Nabel, G. J. (1991) Tumor necrosis factor-alpha, inter leukin 1, and phorbol myristate acetate are independent activators of NF-kappa B which differentially activate T cells. Cytokine 3, 372-379.

Nathan, C. (2002) Points of control in inflammation. Nature 420, 846852.

Ogura, T., Sutterwala, F. S. and Flavell, R. A. (2006). The inflammasome: first line of the immune response to cell stress. Cell 126, 659-662. 
Park, J. C., Hur, J. M., Park, J. G., Kim, S. C., Park, J. R., Choi, S. H. and Choi, J. W. (2004) Effects of methanol extract of Cirsium japonicum var. ussuriense and its principle, hispidulin-7-O-neohesperidoside on hepatic alcohol-metabolizing enzymes and lipid peroxidation in ethanol-treated rats. Phytother. Res. 18, 19-24.

Rankin, J. A. (2004) Biological mediators of acute inflammation. AACN. Clin. Issues. 15, 3-17.

Thornberry, N. A., Bull, H. G., Calaycay, J. R., Chapman, K. T., Howard, A. D., Kostura, M. J., Miller, T. K., Molineaux, S. M., Weidner, J. R., Aunins, J., Elliston, K. O., Ayala, J. M., Casano, F. J., Chin,
J., Ding, G. J., Egger, L. A., Gaffney, E. P., Limjuco, G., Palyha, O. C., Raju, S. M., Rolando, A. M., Salley, J. P., Yamin, T. T., Lee, T. D., Shively, J. E., MacCross, M., Mumford, R. A., Schmidt, J. A. and Tocci, M. J. (1992) A novel heterodimeric cysteine protease is required for interleukin-1 $\beta$ processing in monocytes. Nature 356 , 768 - 774

Vane, J. R., Mitchell, J. A., Appleton, I., Tomlinson, A., Bishop-Bailey, D., Croxtall, J. and Willoughby, D. A. (1994) Inducible isoforms of cyclooxygenase and nitric-oxide synthase in inflammation. Proc. Natl. Acad. Sci. USA. 91, 2046-2050. 